\title{
Tradición e Historia en Congar. Desafío y oportunidades para una renovación en la transmisión de la fe
}

\author{
Alberto Toutin, ss.cc. \\ PONTIFICIA UNIVERSIDAD CATÓLICA DE CHILE \\ FACULTAD DE TEOLOGÍA
}

\section{Un contexto desafiante para la relación entre tradición e historia.}

Ofrecer una presentación sobre la comprensión de la relación entre historia y Tradición -y tradiciones- en Yves-Marie Congar es entrar en un terreno complejo y dinámico. Una primera aproximación a la complejidad de esta articulación es dada ya por las distintas acepciones que tiene en el habla corriente la voz Tradición y que se encuentran recogidas en el Diccionario de la Real Academia Española:

- Transmisión de noticias, de composiciones literarias, doctrinas, ritos, costumbres, etc., hecha de generación en generación.

- Noticia de un hecho antiguo transmitida de este modo.

- Doctrina, costumbres, etc., conservada en un pueblo por transmisión de padres a hijos.

- Elaboración literaria, en prosa o verso, de un suceso transmitido vía oral.

- Entrega de algo a alguien.

- Conjunto de los textos, conservados o no, que a lo largo del tiempo han transmitido una determinada obra ${ }^{1}$.

Una primera dimensión de la complejidad de la tradición tiene que ver con el objeto multiforme de lo trasmitido: noticias de hechos o sucesos,

1 http://buscon.rae.es/draeI/ [consultado el 1 de septiembre de 2010]. 
doctrinas, textos literarios, ritos, costumbres. Una segunda dimensión se refiere a la acción misma implicada en la tradición: transmisión, entrega, conservación, elaboración de textos. Una tercera dimensión tiene que ver esta vez con los actores o agentes de esta tradición, que son sujetos vivos que se encuentran ya implicados en una relación: miembros de una generación, la relación padre-hijo. Una cuarta dimensión toma en cuenta las mediaciones de esta comunicación: la oralidad, la escritura, en distintas formas, en definitiva, el encuentro. Y finalmente, una quinta dimensión dice relación con el medio en que se realiza esta acción, la historia, que no es un mero vehículo o canal aséptico o indiferente a lo transmitido y a quienes lo transmiten sino que los envuelve a ambos y los condiciona mutuamente.

Otra vía que permite sopesar la complejidad de la articulación entre Tradición e historia, es dada, esta vez, por la acción pastoral de nuestra Iglesia y el contexto en el que ella se inscribe. En efecto, en distintos contextos socioculturales se observa una crisis en la transmisión o tradición (entrega) de la fe, en sus expresiones espirituales, celebrativas, dogmáticas, imaginativas, artísticas y normativas, de una generación a otra. En especial, las generaciones jóvenes no reciben o no están en condiciones de recibir dichas expresiones como estructurantes para sus vidas. Lejos de toda moralización apresurada que apuntaría a una mala voluntad o indisposición de los jóvenes, se trata de una situación radicalmente nueva ante la cual los actores de esta transmisión se sienten a menudo sin recursos. Además a los jóvenes los contenidos de la misma les resultan anacrónicos, los canales de socialización y de comunicación de la fe se muestran desfasados y sus lenguajes poco o prácticamente insignificantes.

Es lo que señalan los pastores y laicos reunidos en Aparecida como una de las sombras que desafían hondamente a la Iglesia en la hora presente: «En la evangelización, en la catequesis y, en general, en la pastoral, persisten también lenguajes poco significativos para la cultura actual, en particular para los jóvenes. Muchas veces, los lenguajes utilizados parecieran no tener en cuenta la mutación de los códigos existencialmente relevantes en las sociedades influenciadas por la postmodernidad y marcadas por un amplio pluralismo social y cultural. Los cambios culturales dificultan la transmisión de la Fe por parte de la familia y de la sociedad. Frente a ello, no se ve una presencia importante de la Iglesia en la generación de 
cultura, de modo especial en el mundo universitario y en los medios de comunicación» ${ }^{2}$.

Esta constatación creciente de una crisis de la transmisión de la fe -tanto en sus contenidos como en los actores e instancias que la favorecerían- es la repercusión de un fenómeno más vasto de una crisis de transmisión de sentido de una generación a otra, debido, en gran medida, a una mutación importante del contexto en donde acontece dicha transmisión: Efectivamente, el contexto de mutaciones sociales y culturales rápidas y profundas como la globalización, el pluralismo, la multiculturalidad, la tecnificación de la vida cotidiana, sin desconocer los progresos que representa, opera una transformación de la cosmovisión en cuyo horizonte se despliega la vida humana: los valores, imaginarios, actitudes y criterios humanos y cristianos que tradicionalmente permitían situarse existencialmente. Todo ello incide en la realidad de la Iglesia tanto en los sentimientos de pertenencia por parte de los fieles como en la vivencia, en la comprensión y en la transmisión de la fe. Todos estos aspectos se ven afectados, para bien y para mal, por un proceso creciente de desinstitucionalización o destradicionalización de la experiencia religiosa y de una correlativa individualización y subjetivación de la experiencia religiosa ${ }^{3}$. Por un lado, se observa un fuerte debilitamiento del sentido comunitario, de las pertenencias a colectivos concretos y de los referentes y modelos de vida tradicionales. Por otro, se instalan en su lugar otros modelos que se fundan más bien en el sujeto individual y en su proceso de individualización entendido este como el proceso que hace «que los referentes y valores tradicionales son tomados como opción y no como obligación y, paralelamente, que hay un aumento de la capacidad de los individuos para diseñar o escoger por sí mismos el tipo de vida que desean $»^{4}$. Todo ello no significa que lo religioso-católico desaparezca del espacio social y público sino que se reconfigura, conforme a las oportunidades que ofrece y requerimientos que exige este nuevo contexto social:

«En contexto de individualización ella [la religión] tiende a ser una fuente de sentido subjetivo que cada persona elige, selecciona y organiza de manera más o menos arbitraria para otorgar orientación a sus

2 V Conferencia General del Episcopado Latinoamericano y del Caribe, Aparecida- Documento conclusivo, $100 \mathrm{e})$.

3 Desarrollo Humano en Chile, Nosotros los chilenos. Un desafío cultural (Programa de las Naciones Unidas para el Desarrollo -PNUD-), (Santiago 2002) 234-241.

4 Desarrollo Humano en Chile, Nosotros los chilenos. Un desafío cultural, 192. 
proyectos personales» ${ }^{5}$. En el proceso de reconfiguración de lo religioso, existe pues una dificultad para muchos de los contemporáneos tanto para vivir como para transmitir y comunicar de manera significativa los valores, prácticas, conocimientos e imaginarios religiosos católicos que informaron su vida e inspiraron sus opciones a una nueva generación. Esta, por su parte, se ve enfrentada a nuevas preguntas que sus mayores no conocieron: amor en tiempos de inestabilidad, movilidad y precariedad laboral, tecnificación de la vida, etc. Además la generación de los jóvenes se muestra particularmente reticente a modelos valóricos y religiosos que se les impongan y que no se hayan hecho cargo de su realidad, de su gramática o códigos de lenguaje, no solo en su condición de destinatarios sino también como interlocutores capaces o, al menos, deseosos de decidir y organizar dichos modelos para dar sentido a sus proyecto biográficos o personales.

En este contexto presentaremos algunos de los elementos principales que caracterizan la comprensión de la Tradición y el vínculo de esta con la historia en el pensamiento de Yves-Marie Congar, o.p. (1904-1995). Esta presentación apunta a poner en perspectiva crítica a los elementos contextuales antes señalados y a ofrecer elementos para un discernimiento sobre los desafíos y oportunidades que existen en este contexto para hacer presente de manera significativa el Evangelio que hemos recibido.

\section{Tradición e historia en Congar}

En una primera aproximación a la realidad de la Tradición, Congar la caracteriza de la manera siguiente:

«La tradición es una entrega mediante la cual el don del Padre se comunica a un gran número de hombres a través del espacio y en la sucesión de las generaciones, de tal manera que una multitud de individuos, materialmente separados por la distancia y por los años, viven de una misma e idéntica Realidad que es el don del Padre y, en primer lugar, la verdad salvadora, la Revelación divina realizada en Jesucristo. Esta es comunicación de un tesoro que permanece idéntico a sí mismo: es victoria sobre el tiempo y su caducidad, sobre el espacio y alejamiento de la distancia» ${ }^{6}$.

5 Desarrollo Humano en Chile, Nosotros los chilenos. Un desafio cultural, 239.

6 Y.M. Congar, La tradición y la vida de la Iglesia. Traducido por F. Revilla (Yo sé, Yo creo 3; Casal I Vall (Andorra 1964) 19. Esta obra es una presentación más sucinta y pensada para un público amplio, de su estudio consagrado al tema de la Tradición y 
En esta definición se encuentran sintetizados todos los elementos que componen la realidad compleja de la Tradición y su nexo con la historia.

Su contenido: el don del Padre, y en primer lugar, la verdad salvadora, la Revelación divina realizada en Jesucristo. No se trata entonces de un contenido periférico o marginal de la fe. $\mathrm{Ni}$ tampoco es un listado de verdades o de normas sino Alguien, Dios que se dio y comunicó definitivamente en su Hijo Jesús y que ahora Resucitado desea seguir dándose y ofreciendo su vida por la humanidad, mediante su Espíritu.

Los actores implicados: se trata de todos aquellos que, tras la revelación de Dios acontecida de una vez en Jesús, han recibido y entregado este acontecimiento a las futuras generaciones. Entre estos actores destacan el sujeto trascendente, el Espíritu y el sujeto histórico, la Iglesia. En esta destacan en primer lugar los apóstoles y su generación que recibió y puso por escrito, inspirada por el Espíritu, las palabras y hechos de Jesús y su impacto en las primeras comunidades apostólicas. Y también sus sucesores y los fieles, que asistidos por el mismo Espíritu, despliegan, actualizan e interiorizan la acción de Jesús.

El proceso de la tradición: consiste en un recibir y dar, el proceso de comunicación, de profundización y de actualización de una relación entre el Señor Viviente y los hombres y mujeres de todo tiempo y lugar, relación que se hace existencialmente contemporánea de ellos.

Contenido, sujetos y proceso de la Tradición se condicionan e implican mutuamente en la realidad compleja de la Tradición. Detengámonos en cada uno de estos elementos, destacando en ellos su estrecha vinculación con la historia, como contexto y medio de la Tradición.

\section{El contenido de la Tradición}

Dos elementos caracterizan de manera constante la comprensión de la Tradición en Congar. Por un lado, que lo transmitido no es algo fijo, estático, sino Alguien vivo, dinámico. Al punto que es toda la Tradición la que es cualificada por quien es así transmitido: es la Tradición viva. Por otro, toma distancia de una comprensión historizante y meramente documentaria de la Tradición, según la cual su contenido verídico es aquel del que

las tradiciones. Y.M.Congar, La Tradition et les traditions. Essai historique (I) Essai théologique (II) (Le Signe; Arthème Fayard, Paris 1960). 
se pueden proveer las piezas documentales, comprobables mediante los procedimientos historiográficos.

Para comprender mejor el alcance del contenido de la Tradición, Congar distingue entre el aspecto más objetivo de la misma, entendido como la creencia común y unánime de la Iglesia, considerada no solo en su actualidad sino incluso a lo largo de la historia; es la manera de ser cristiano común a los fieles de ayer y de hoy, recibida de los primeros cristianos y de los apóstoles. Este contenido es católico total, que supera con mucho lo que de él se encuentra formulado (tradiciones apostólicas escritas y no escritas) y todavía más lo que hemos comprendido y seríamos capaces de explicar. Lo que ha sido transmitido no es solo un enunciado teórico, ni siquiera una profesión de fe, sino la realidad misma del cristianismo, siempre presentes, especialmente en la Palabra proclamada y acogida en la Iglesia y en los Sacramentos.

El sentido subjetivo, corresponde al modo como dicha realidad presente es recibida por los testigos. Congar llama a este sentido subjetivo de la Tradición el sentido católico, entendido como «cierto instinto, sentimiento o disposición íntima debida a la conciencia que la Iglesia tiene de su propia identidad y de lo que pudiera hacerla peligrar»?

Llamamos la atención sobre el hecho que la catolicidad de la Tradición se refiere tanto a la realidad presente y relacional que define al cristianismo (contenido), expresada en las formas variadas y jerarquizadas como a los sujetos que la acogen y viven de ella (actores).

Esta articulación entre el contenido de la tradición y los sujetos es posible por cuanto la tradición atañe también al proceso de la «transmisión vital del cristianismo» y por esta vía "es poseído y tenido en su totalidad y como totalidad más allá de lo que se pueda comprender y formular del mismo e incluso más allá de lo que se pueda justificar mediante referencias externas de tipo histórico-crítico» ${ }^{8}$. En esta perspectiva, Congar está lejos de oponer una transmisión viva y una concepción historiográfica de la misma, en primer lugar, por el hecho de que el contenido fundamental de la Tradición -Dios que se comunica, especialmente en Jesús de Nazaret muerto y resucitado- aconteció en una historia y cultura particular, cuyas huellas e impacto en los que lo encontraron son efectivamente identificables historiográficamente. Luego, la actitud subyacente a los testimonios

7 Y.M. CONGAR, La tradición y la vida de la Iglesia, 36.

8 Y.M. Congar, La tradición y la vida de la Iglesia, 30 
historiográficos es la misma que anima a la Tradición como transmisión vital del cristianismo, a saber, como expresión de la manera como la comunidad recibió, vivió y plasmó la vitalidad del cristianismo tradicional. Sin embargo, Congar advierte que la comunicación vital del cristianismo no se agota ni es reducible a sus testimonios historiográficamente comprobables, como tampoco, mutatis mutandi, la obra escrita de una persona agota su paso y su devenir por la historia.

A ello se añade el hecho de que la realidad de la Tradición no solo está residualmente viva en la memoria de los que conservan su recuerdo sino también su gesto y su entrega se actualizan existencialmente para cada hombre y cada mujer en la fe de los que viven del Resucitado, en la comunidad -la Iglesia - que visibiliza especialmente su presencia y su actuar. La tradición se la aprecia, por tanto, en su real valor no solo ni exclusivamente por los documentos historiográficos que atestiguan su veracidad sino también y sobre todo, en los testigos que en sus propias vidas verifican la realidad siempre actual y presente de la acción del Resucitado. Estos ofrecen una síntesis vital del Viviente, síntesis que implica elementos históricos por cierto pero también intelectuales, afectivos, morales. La Iglesia, como el conjunto de los testigos que creen en Jesús, profundiza la Tradición que ha recibido de los Apóstoles -en la fase constitutiva de la revelación- y la recibe en la circunstancia inédita del hoy, asistida por el Espíritu Santo para ver en donde está actuando el Señor Resucitado: «Reflexionando sobre los textos y sobre los hechos, cobrando conciencia de lo que implica la experiencia que verifica de las realidades santas que la habitan, releyendo una vez más los textos a la luz de esa experiencia, la Iglesia llega a reconocer, con la confirmación divina, un contenido más rico que lo que pudiera resultar de una simple lectura histórica de los textos, sin más»?

\section{Sujetos de la tradición}

Si bien Congar introduce la noción de sujeto de la Tradición, en correlación con el objeto o contenido de la misma, sin embargo, esta distinción es más formal que real en la medida en que el contenido de la Tradición no es un objeto fijo sino un Sujeto actuante -Dios que se manifestó de una vez para siempre en Jesús- que sigue comunicándose y comunicando la fuerza de este acontecimiento cuando hombres y mujeres en la historia

9 Y.M. CONGAR, La tradición y la vida de la Iglesia, 134. 
lo hacen suyo. Puesto que la Tradición es la comunicación vital de relación religiosa - filial y fraternal- de Dios en Jesús por su Espíritu, ella se hace presente en una relación entre dos sujetos: El Espíritu Santo como sujeto trascendental de la Tradición y la Iglesia como sujeto visible e histórico de la Tradición. Estos dos sujetos interactúan de manera sinérgica y asimétrica, mutuamente implicados en una misma historia.

El Espíritu, por ser Espíritu de Cristo, en los tiempos apostólicos -por inspiración- y posapostólicos - por asistencia- «actualiza e interioriza lo que fue dicho y hecho de una vez para siempre por Cristo, es decir, el Evangelio (cf. Jn 14, 26; 16, 12-13)» ${ }^{10}$.

Esto significa que la vida según en el Evangelio, cuyos rasgos esenciales se hicieron visibles de una vez para siempre en la misión histórica y visible del Verbo Encarnado, apunta precisamente a ser conocida y ofrecida como una forma válida para todos los tiempos, que debe por tanto extenderse al mundo y a la historia, aplicándose a la infinita variedad de situaciones y de personas. Lo propio de la acción del Espíritu es su nexo indefectible tanto al acontecimiento único de Jesús, en su vida y su historia como en su realidad presente y actuante resucitada. Y, a la vez, en cuanto Espíritu del Resucitado, él actualiza, universaliza e interioriza el pro nobis que define el ser, las actitudes y las acciones de Jesús. Esta comprensión de la acción cristificante del Espíritu reposa sobre lo que el mismo Congar desarrolla en lo que él llama una «cristología pneumatológica» ${ }^{11}$. Esta recomprensión del único y definitivo acontecimiento de Cristo busca poner de relieve no tanto las relaciones eternas intratrinitarias entre el Verbo y el Espíritu sino más bien la estrecha relación histórica que se dan entre Jesús muerto y Resucitado y el Espíritu: en el estado de kénosis en donde Jesús aparece como el Ungido por el Espíritu y guiado por Él y en el estado glorioso, en donde Jesús, Señor Resucitado aparece como Señor que comunica su Espíritu y a través de este -Dios en nosotros- nos hace hijos adoptivos del Padre y hermanos de Jesús.

La relación indisociable que se da por naturaleza entre el Señor Resucitado y su Espíritu, se mantiene también en la realidad de la Iglesia -isu Iglesia!- en cuanto cuerpo social que visibiliza en la historia la presencia de Cristo. El Espíritu del Resucitado es coinstituyente de la Iglesia, la

\footnotetext{
10 Y.M. CONGAR, La tradición y la vida de la Iglesia, 52.

11 Y.M. Congar, El Espiritu Santo. Traducido por A. Martínez de Lapera (Barcelona 1983), 598-603.
} 
que no tiene otro fin que hacer visible y presente al Señor Resucitado en la historia. De esta unión de la acción del Espíritu en el testigo de Jesús Resucitado habla Pablo cuando formula el criterio cristológico de discernimiento de la acción del Espíritu: «Nadie puede decir: "Jesús es el Señor" si no lo hace movido por el Espíritu Santo» (1Co 12, 3). Lo que el Espíritu hace en cada creyente, lo hace también en el conjunto de la realidad de la Iglesia, en sus distintas actividades, ministerios y carismas, así como en las distintas expresiones -dogmáticas, litúrgicas, normativas, artísticas- en las que se le da cuerpo y rostro humano a la acción del Resucitado. Retomando una imagen de Ireneo de Lyon, Congar expresa esta acción conjunta del resucitado y de su Espíritu en la marcha de la Iglesia, como las «dos manos» ${ }^{12}$ Cf. Ireneo de Lyon, Adversus Haereses V, 6, 1; V, 28, 4. de Dios: «La Iglesia aparece así provenir a la vez del Verbo en su Encarnación y del Espíritu -o del Señor Glorificado-incesantemente activo al interior de las personas como de las estructuras sacramentales y jurídicas. Verdaderamente, Dios opera con sus dos manos conjuntas» ${ }^{13}$.

Esta acción cristificante del Espíritu se verifica entonces ad intra ecclesiae. Dicha acción no anula la condición creatural, pecadora y peregrinante en el tiempo de sus miembros. Si bien a la Iglesia, como a su cuerpo, el resucitado le ha prometido la asistencia indefectible de su Espíritu, no todo lo que la Iglesia hace y dice es obra del Espíritu del Resucitado. Dicha acción requiere ser discernida por el conjunto de la Iglesia, teniendo en cuenta sus diferentes instancias y actores, en los niveles de corresponsabilidad que les competen, así como una suerte de gradación -jla expresión es infeliz!- de la presencia del Espíritu operante en ella: «Existe una gradación muy matizada y compleja en lo que pudiera llamarse su compromiso [el del Espíritu] en lo humano de la historia de la salvación y que va desde su don perfecto a Cristo a los trabajosos tanteos de los teólogos, pasando por las gracias concedidas a los apóstoles, a los profetas, a los Padres, a los grandes pontífices o a los fundadores religiosos... ${ }^{14}$.

Congar insiste también en la atención que la Iglesia ha de prestar a la acción del Espíritu ad extra ecclesiae, en las experiencias de la mundanidad del mundo, en su implicación en los acontecimientos y movimientos históricos en favor de condiciones de vida más humana para todos, leyendo

\footnotetext{
12 Cf. Ireneo de Lyon, Adversus Haereses V, 6, 1; V, 28, 4.

13 Y.M. Congar, La Parole et Le Souffle (Jésus et Jésus-Christ 20; Paris 1983) 135.

14 Y.M. CONGar, La tradición y la vida de la Iglesia, 54.
} 
a la luz del Evangelio los signos de los tiempos: «El Pueblo de Dios, movido por la fe, que le impulsa a creer que quien conduce es el Espíritu Santo, que llena el universo, procura discernir en los acontecimientos, exigencias y deseos, de los cuales participa juntamente con sus contemporáneos los signos verdaderos de la presencia o de los planes de Dios» (GS 11, 1).

El Espíritu Santo que asiste a la Iglesia, y que opera discreta y eficazmente en el mundo, la pone a ella entera en una dinámica de descentramiento de sí para estar efectivamente centrada en la acción de Dios en la historia y en el mundo. De este modo, la Iglesia asume su propia mundanidad e historicidad que le son constitutivas en virtud de la presencia operante del Espíritu que la sostiene y la precede.

Esta comunicación en la Tradición de lo que Dios es por lo que él hace en favor de la humanidad conlleva una verdadera sinergia de los todos los actores implicados en dicho proceso. Cada uno en su ámbito y nivel de corresponsabilidad está llamado a hacer visible eso que el Espíritu del resucitado está realizando por todos. Magisterio pastoral, teólogos y pueblo fiel en su conjunto están llamados a colaborarse en la tarea del discernimiento y de la visibilización de la acción del Espíritu de Dios. Dicha acción se hace patente de modo especial en los testigos cuyas vidas son una respuesta creíble a lo que Dios por su Espíritu hace en favor de ellos. En este sentido, los fieles no se contentan simplemente con una conservación y transmisión de la Tradición, no devuelven al Magisterio pastoral un mero «eco de su enseñanza», sino algo que realiza una recepción original, produciendo algo inédito como «el eco de unos sujetos vivos» ${ }^{15}$ en una auténtica colaboración entre la jerarquía y fieles así como entre las iglesias particulares entre $\mathrm{si}^{16}$. Pero esta colaboración se funda en otra sinergia más fundamental que es la que acontece en el corazón del ser humano entre el Dios que se abre paso entre las aspiraciones, obstáculos anhelos y esperanzas del hombre. Allí se entregan y reciben mutuamente como sujetos vivos. Una vez más, la realidad misma del Dios cuyo ser lo conocemos por la relación que establece con la humanidad y por lo que continúa haciendo en su favor requiere el concurso de las energías y de las mejores capacidades de todos los fieles. La riqueza siempre desbordante de Dios

15 Y.M. CONGAR, La tradición y la vida de la Iglesia, 70.

16 Sobre la recepción como dinámica eclesial que hace la verdad de lo transmitido por la Tradición. Cf. Y.M. Congar, «La "réception" comme réalité ecclésiologique», en Revue des Sciences Philosophiques et Théologiques 56 (1972) 369-403. 
brilla así de manera más homogénea con esta realidad, en la diversidad también inédita de ministerios y carismas que interactúan en la Iglesia.

Congar precisa de qué manera los fieles, con sus competencias, contribuyen a la transmisión viva, recepción y comunicación eclesialmente mediada de la Tradición y a su desarrollo multiforme en el tiempo:

«Lo hacen con la piedad y el ejercicio de su vida religiosa. Es un hecho que así han contribuido poderosamente a desplegar la creencia de la Iglesia, por ejemplo, en lo referente al misterio mariano: se ha visto en el dogma de la Inmaculada Concepción. Pero asimismo lo hacen mediante el estudio científico de las fuentes de la fe y de los monumentos de la Tradición, mediante la reflexión filosófica e incluso teológica, mediante las creaciones artísticas y culturales que afectan la religión, y mediante sus iniciativas apostólicas y misioneras, sin contar todo lo que monjes y hombres de elevada espiritualidad que no fueron sacerdotes han aportado al tesoro de la espiritualidad cristiana» ${ }^{17}$.

\section{Proceso de la tradición}

Dado que lo que se transmite es la relación religiosa, la relación que Dios establece con la humanidad y que para actualizarla y profundizarla, requiere de las mejores energías y de los recursos con los que cuentan los actores implicados en ella, lo que define a la Tradición como proceso es que es del orden de una comunicación viva. Esto supone no solo conocer las normas que rigen toda comunicación humana y someterse a ellas -atención al mensaje, al emisor y al receptor/interlocutor y al contexto en que se da dicha comunicación- sino también acoger la comunicación específica que Dios estableció con la humanidad, en especial al entrar en la historia de un pueblo y hacer alianza, a través de él, con toda la humanidad. En este sentido, la Tradición comporta una dimensión comunicativa que abraza toda la historia en virtud de la modalidad misma mediante la cual Dios entra en comunicación con nosotros.

Esta idea madura poco a poco en Congar y se va a consolidar durante el año de exilio que vivió en Jerusalén en 1954. Allí profundiza sus conocimientos bíblicos que van a enriquecer de manera decisiva su comprensión de Dios. Pasa de una visión de cuño más tomista, esencialista, centrada en los atributos de Dios como absoluto, a una visión más bíblica, existencial, centrada en la relación que Dios quiere establecer con la humanidad. Así

\footnotetext{
Y.M. CONGAR, La tradición y la vida de la Iglesia, 71.
} 
lo explicita años más tarde cuando es consultado acerca de su visión de Dios. Por un lado, se opone a las imágenes de un Dios en sí que parecería desentenderse de su compromiso real con la historia de la humanidad, ya sea en la figura del gran arquitecto o del relojero del mundo, de un Dios que habría actuado en el impulso inicial de la creación para luego desaparecer. Por otro, afirma que su imagen de Dios es de fuerte raigambre bíblica, el Dios vivo, activo y presente, un Dios que está volcado hacia la humanidad y entra en relación permanente con ella. Para referirse a Dios habría que llamarlo, estima él, en una sola frase: «Dios-que-hizo-salir-a Israel- de Egipto». «Dios-que-ha-hecho-alianza». El Dios de la Biblia es «Yo soy- yo era- yo vengo», [...] y siempre el Dios que ha hecho alguna $\operatorname{cosa}^{18}$.

Una vez admitido que Dios en su diálogo con la humanidad, asume la historicidad para hacerla lugar de encuentro salvífico con él, Congar saca una consecuencia fundamental que concierne tanto el conocimiento que podemos tener de Dios como los modos de hacerlo visible y de comunicarlo a los demás. Se trata de la aproximación a Dios desde su economía, es decir, desde «la gestión del mundo por Dios en vista de la salvación. Y el conocimiento económico de Dios - por tanto, a través de lo que Él hacenos lleva a conocer lo que Él es en sí mismo: Él es según lo que hace y hace segín lo que Él ess ${ }^{19}$. Esta afirmación implica reconocer que la historia no es ajena al quehacer y ser de Dios, sino que al contrario es el espacio mediador en donde lleva su acción salvífica y en donde la humanidad, en la fe, puede abrirse a esa misma acción. Dicho de otro modo, el compromiso de Dios con la historia -máxime en Jesús, en que el Verbo se hace historia, cultura, carne- es expresión de su estar permanentemente volcado hacia la humanidad y en donde atisbamos su ser en el eterno interrelacionarse del Padre, del Hijo y del Espíritu. Esta aproximación económica a Dios entraña también para la Tradición la tarea del discernimiento, de reconocimiento y de colaboración en el hoy de esta relación salvífica de Dios con toda la humanidad. La Tradición está entonces normativamente orientada al servicio de esta relación de Dios actuante y actual de Dios. Para ello ha de buscar y crear los modos de comunicación que le sean más adecuados al Dios que así actúa y a la humanidad en cuyo favor opera.

18 J. PuYo, Une vie pour la vérité. Jean Puyo interroge le Père Congar (Paris 1975) 171-172.

19 J. Puyo, Une vie pour la vérité. Jean Puyo interroge le Père Congar, 173. El destacado es de Congar. 
Por lo mismo, la realidad misma de la Tradición - en su contenido indisociable de sus modos de comunicación en la Revelación y de actualización mediante la Tradición- requiere de sujetos vivos, de testigos que vivan de «lo que han recibido» en la fe y ellos mismos, a su vez, en sus modos de entenderse, de relacionarse con los demás, de actuar, «entreguen» a los otros, de manera veraz y creíble la realidad viva que los sostiene. Se trata de vivir como testigo de un encuentro con el Dios vivo, el cual reconfigura la existencia cristiana, introduciéndole un nuevo principio de acción y urgiéndola a una radical coherencia de vida: «Yo ya no vivo, sino Cristo vive en mí». (Gál 2, 20) Al modo de Pablo y de tantos otros hombres y mujeres, creyentes en la historia, el Espíritu de Jesús actualiza la presencia del Resucitado en los testigos que este mismo Espíritu suscita. La relación personal de Dios con su Pueblo, el don de su filiación adoptiva en Jesús por el Espíritu, se hace visible y operacional en la realidad de los testigos que así viven: «La tradición, como medio en que recibimos el cristianismo y somos formados según él, no existe sino por medio de quienes, habiéndola recibido, viven de ella y la transmiten a otros, para que estos vivan de ella a su vez. Es, como la educación, una comunicación viva; es la comunicación cuyo contenido es inseparable del acto con que una persona viva hace beneficiaria de ella a otra persona viva» ${ }^{20}$.

Por la unión indisociable que existe en el núcleo de la tradición entre lo que Dios es y lo que él hace y continúa haciendo en favor de la humanidad, la atención prestada a la historia en toda su contingencia y su permanente devenir, corresponde a un acto de fidelidad al Dios que así se reveló y sigue actuando. De este modo, la novedad de la acción presente de Dios requiere ser discernida en las circunstancias siempre inéditas y cambiantes de la historia. De algún modo, la acción definitiva de Dios manifestada ya en Jesús, de una vez para siempre, es profundizada y desplegada en las coordenadas dinámicas de la historia, con sus interrogantes y desafíos propios, a la vez que mantiene a los testigos abiertos a esa acción-porvenir de Dios cuando el Señor Resucitado vuelva en su Gloria y Dios «sea todo en todos» (1 Co 15, 28):

«La Tradición es algo vivo porque es vehiculada por unos espíritus vivos, y que viven en el tiempo. Estos encuentran en él unos problemas o adquieren unos recursos que les llevan a dar a la Tradición, o a la verdad que la misma contiene, las formas y las reacciones de una cosa viva: adaptación, reacción, crecimiento, fecundidad. La Tradición

20 Y.M. CONGAR, La tradición y la vida de la Iglesia, 29. 
es algo vivo porque la sostienen unos espíritus que viven de ella en la historia, una historia que es actividad, problemas, discusiones, aportaciones y exigencias de respuesta» ${ }^{21}$.

Todos estos esfuerzos de adaptación requeridos por el contenido mismo de la Tradición no son meramente pragmáticos que, en el sentido que apuntarían a que el mensaje pase mejor o sea mejor recibido. Ello comporta una renovación en la comprensión de ese mismo mensaje del que la Iglesia es portadora en la medida en que acoge esas preguntas y desafíos inéditos que plantea el presente histórico y se dota de recursos categoriales nuevos, acordes con el carácter también inédito de la acción de Dios en la historia. De alguna manera, el contenido mismo de la Tradición y los actores implicados en su fidelidad testimonial se ven renovados al procurar nuevas formas de expresión. La relación contenido y forma no es de extrinsecismo mutuo sino que se hallan mutuamente referidos y condicionados. Congar describe en la imagen elocuente de la arteria esta interacción entre forma y contenido que se opera en la transmisión de la Tradición:

«En el acto mismo en que es canal, por no ser un canal mecánico, sino viviente, es también fuente en cierto modo. Alimentando los tejidos, la sangre se regenera también en las arterias que la vehiculan. La Tradición es arteria viva que, en el acto mismo de transmitir, recibe un crecimiento de la vida misma que comunica» ${ }^{22}$.

Con todo, Congar articula estas exigencias de adaptación inherentes a Tradición con las exigencias no menos importantes de fidelidad al contenido de la misma, en su carácter irreductible. En este sentido, toma distancia de lo que él califica como un «relativismo de la verdad» que «no es otra cosa que el pensamiento sucesivo y cambiante de los hombres», una dilución del contenido objetivo y de la pretensión de verdad aneja a ese contenido, en el proceso de la transmisión viva en la historia. «La Tradición no implica ni siquiera soporta alteración alguna en su contenido objetivo. Es comunicación de un ser vivo a otro, pero comunicación de un objeto definido y que permanece idéntico en su naturaleza profunda» ${ }^{23}$.

En la relación indisociable que existe al interior de la Tradición entre su objeto -Él es lo que hace por nosotros- y sus modalidades - relacionales históricas- según las cuales se da conocer y se actualiza, todo el

\footnotetext{
21 Y.M. CONGAR, La tradición y la vida de la Iglesia, 72.

22 Y.M. Congar, La tradición y la vida de la Iglesia, 108.

23 Y.M. CONGAR, La tradición y la vida de la Iglesia, 101.
} 
trabajo teológico reside en mantener la tensión, lo más fecunda posible, entre la necesaria adaptación de formas de expresión y de inteligibilidad de la Tradición y la conservación de la naturaleza profunda e irreductible de su contenido. Esta tensión se ha de orientar tanto por el ideal de plenitud -de lo que aún está por venir y manifestarse de Dios y su acción en la historia- como por un ideal de pureza- respecto a lo que hemos recibido de nuestros predecesores, desde los Apóstoles a nuestros días.

«Toda la historia de la Iglesia está atravesada por una tensión entre un ideal de plenitud y un ideal de pureza. El primero inclina a buscar la apertura, la acogida y el movimiento, la síntesis con lo que se le presenta, pero entraña el peligro de perder la pureza. Esta debe reafirmar continuamente sus exigencias, en nombre de los principios originales cuyo testimonio más inmutable, más íntegro y más indiscutible presentan las Sagradas Escrituras. Por ello, estas son una referencia crítica necesaria para todo desarrollo o crecimiento de la Tradición» ${ }^{24}$.

\section{Acerca del arte de la transmisión de la Tradición. Notas de una sinfonía inconclusa}

Con este telón de fondo de las grandes líneas del pensamiento de Congar sobre los vínculos entre la Tradición y la historia, volvamos a las preguntas iniciales que sitúan hoy la problemática de la crisis de la transmisión de la Tradición a las nuevas generaciones y precisemos de manera específica el trabajo que le incumbe a la teología.

\section{Al servicio de lo inédito y porvenir de la acción de Dios en la historia}

La fidelidad al objeto/sujeto de la Tradición como a su dinámica comunicacional propia - de un ser vivo a otro en la historia- es la que justamente pone a los sujetos que colaboran en su transmisión en una situación de una inconfortable inestabilidad. Es cierto que, a lo largo de la historia, la Iglesia ha ido institucionalizando algunas distintas formas de expresión - escrita y no escrita- sacramental, dogmática, normativa, exegética, artística mediante las cuales se ha hecho visible para el hoy de cada época, la relación kairótica de Dios con la humanidad. Esta relación tiene su paradigma en la relación establecida por Dios, de una vez para siempre, en la humanidad crucificada y resucitada de Jesús de Nazaret. La fidelidad al Dios de Jesús y al Dios de nuestros Padres conlleva entonces una atención al carácter siempre nuevo y por venir -desde Dios para nosotros- de esa

24 Y.M. CONGAR, La tradición y la vida de la Iglesia, 140. 
relación de Dios en el transcurso de tiempo y al carácter también nuevo de los desafíos, inquietudes y anhelos que trabajan abierta o secretamente a la humanidad.

Desde el punto de vista de la Tradición como proceso comunicacional, las mismas formas en que se ha ido plasmando llevan en sí y hablan a la vez de las circunstancias - preguntas o desafíos- que les dieron origen. Recibir estas formas para iluminar el presente con su novedad involucra un trabajo hermenéutico parte de la teología de resignificación de esas formas en los nuevos contextos en que son leídas y asumidas. Sin embargo, hoy nos enfrentamos a desafíos culturales de tal envergadura que dicho esfuerzo interpretativo requiere ser llevado adelante con un nuevo vigor. Pensemos tan solo en los avances tecnológicos y su impacto en dos áreas como son las comunicaciones y la salud. La novedad que estas introducen entre nosotros sobre la comprensión de la vida humana -de su inicio, calidad de vida y su fin- sobre lo que significan los vínculos comunicacionales, las nuevas formas de lo presencial-virtual, son de tal magnitud que por mucho que interroguemos a la Tradición a la luz de estos nuevos cuestionamientos, las respuestas que surjan estarán marcadas por un desfase inevitable entre las matrices culturales de la Tradición y las nuevas coordenadas culturales en que nos situamos. «Hay que echar el vino nuevo en pellejos nuevos, y así ambos se conservan» (Mt 9, 17) respondía Jesús a lo que lo criticaban porque sus discípulos no se moldeaban a las formas de ayuno entonces normativas para la piedad judía.

La novedad de la acción de Dios hoy en la movediza y vertiginosa realidad de la historia exige de la Tradición y de los distintos sujetos que la reciben y transmiten un trabajo que no se puede contentar con una adaptación de formas - permaneciendo el contenido radicalmente inalterable- sino que exige en fidelidad a esta novedad del actuar de Dios en el hoy, lo que Von Balthasar llama un trabajo de fundición: «conocer, repensar y apropiarse de manera originaria y nueva la revelación entera para cada época» ${ }^{25}$. Este trabajo de fundición viene exigido no solo por las circunstancias históricas cambiantes que dictarían los cambios -formales y de comprensión- que deben introducirse en la Tradición sino también y sobre todo, por la misma Tradición que hace que su contenido mistérico

25 H.U. von Balthasar, ¿Qué es un cristiano? Traducido por A. Sánchez Pascual (Omega 10; Madrid 1967), 45-46. 
no pueda ser encapsulado en una fórmula única y rígida, so pena de incurrir en las diferentes formas de idolatría.

A quienes se dedican a la teología entendida como «la forma o el cultivo científico de la fe, que toma en una razón humana utilizando para su mejor comprensión sus recursos racionales» ${ }^{26}$, les corresponde un ejercicio de racionalidad de la fe que dé cuenta de la legitimidad de su acceso singular a la multidimensionalidad de lo real y de sus condicionamientos mutuos en confrontación crítica con otros sistemas sectoriales de interpretación de lo real. Este ejercicio además tiene por un lado, un sentido propositivo, que apunta a «designar en el presente» - en expresión de David Tracy- de la Iglesia y del mundo, la acción siempre inédita de Dios, y por otro, un sentido crítico respecto a toda forma que, desde la precariedad de su propia relatividad hermenéutica y teológica, pretenda encapsular la realidad inobjetualizable del misterio de Dios.

\section{Un nuevo ropaje cultural para la Tradición}

En su lectura de la realidad de la Tradición, Congar subraya el valor que tienen en ella las tradiciones que «son maneras de obrar y de expresar la fe, unas costumbres, unos ritos, unas disposiciones prácticas, toda suerte de determinaciones concretas, asimismo heredadas, que forman una cierta disciplina de la vida cristiana» ${ }^{27}$. Entre estas tradiciones se cuentan el ayuno pascual, el bautismo de niños, el culto a las imágenes, las oraciones fúnebres, etc." ${ }^{28}$. En efecto estas tradiciones obedecen al esfuerzo constante de la Iglesia de dotar de un ropaje cultural adecuado a los contenidos fundamentales de la fe y que se expresan en formas doctrinales, litúrgica, rituales, disciplinares, normativas y artísticas. Dichas formas configuran una cosmovisión, ordenadora de la existencia, que surge como resultado de un trabajo creativo de los distintos actores de la Iglesia por articular la vitalidad de la fe con las formas de la creencia y de pensamiento que se ofrecen en cada época. Incluso más, la fe tradicional recibida de los padres ha sido capaz, en muchos períodos de la historia, de engendrar y de promover formas culturales nuevas de expresión. Pensemos en lo que ha significado como contribución al pensamiento de la humanidad la noción

\footnotetext{
26 Y.M. CONGAR, La tradición y la vida de la Iglesia, 109.

27 Y.M. Congar, La tradición y la vida de la Iglesia, 137.

28 Para una presentación detallada de estas tradiciones Cf. Y.M. Congar, La Tradition et les traditions. (I) Essai historique (Paris, 1960), 64-76.
} 
de persona o algunas expresiones del arte religioso, como las obras de Miguel Ángel Buonarroti en la Capilla Sixtina o Henri Matisse en la Capilla de Vence o en un contexto más nuestro las escultura de Peter Horn y los retablos de Claudio Di Girólamo. En definitivas estas tradiciones son las que crean un medio, un hogar, un contexto que no solo cualifica la cultura de una época dada sino que permite la socialización de los valores, conocimientos, normas e imaginarios que constituyen la Tradición. «Las tradiciones son también los medios humildes de un calor sin el que nuestra Iglesia, más que un hogar, parecería una sala de escuela del siglo pasado: forman ese clima de calor, de familiaridad y de seguridad propio de una casa habitada, de una mansión familiar. No obstante, no tienen el mismo valor de absoluto que la Tradición de la fe. Son más bien el ropaje de esta» ${ }^{29}$.

Sin embargo, Congar constata que hoy en día existe una suerte de despojamiento del ropaje cultural de la fe, en parte debido al hecho que las formas en las que tradicionalmente se la ha revestido no resultan significativas para el hombre y mujer de hoy y, en parte, por un exilio -voluntario u obligado- de los creyentes de los espacios generadores de cultura. Congar habla de una suerte de iconoclasmo contemporáneo de la fe que hace que no posea ni se la haya dotado de imágenes culturales que expresen adecuada y sólidamente para el hoy una visión de la existencia cristiana.

«Estoy convencido por una parte que la fe, [...] tiene necesidad de una expresión cultural, de ceremonias, del arte, de la belleza, de la literatura, de la música. Empero, hoy el medio cultural no es favorable a ello, aun cuando exista un sentido espiritual real en ciertos artistas, sobre todo fuera de la Iglesia. Lo que antes existió del revestimiento cultural católico y cristiano en diferentes ámbitos del arte, de la literatura y de la música, hoy es bastante débil o se limita a grupos a menudo marginales, en una suerte de subcultura $\aleph^{30}$.

Ya no existe un medio cristiano que sea espiritualmente consistente como para atraer y engendrar formas culturales nuevas y suficientemente contundentes en las que la Tradición hable en católico, es decir hable la lengua de los hombres y mujeres de hoy. Se trata de formas dotadas de la fuerza configuradora de mentes y de existencias que se ofrezcan como caminos de sentido -y de salvación como felicidad ofrecida (por Dios) - a quienes quieran recorrerlos. Esta tarea incumbe de modo particular a la

29 Y.M. Congar, La tradición y la vida de la Iglesia, 138.

30 Y.M. Congar, Entretiens d'automne. Présentés par Bernard Lauret (Paris 1987), 89. 
teología entendida ella misma como una expresión en el orden de la inteligencia del diálogo entre la fe y la cultura, en un momento dado de la historia. Bajo este respecto, la teología es, según Congar «la cultura de la fe por el uso honesto de los medios de cultura disponibles en un momento dado» ${ }^{31}$. La teología tiene en sí una vocación cultural y es generadora de cultura, como expresión del dinamismo de la fe, de su carácter englobante del conjunto de la persona y de sus relaciones. Muestra de la vitalidad de fe es precisamente una teología, capaz de utilizar con discernimiento crítico los recursos de la racionalidad humana para dar que pensar la novedad permanente de Dios volcándose hacia la humanidad y su relación con las cuestiones fundamentales a las que todo ser humano, tarde o temprano, se enfrenta en su propia tarea de existir.

\section{De la selección a la elección}

El contexto actual en que constatamos una cierta crisis de transmisión de la fe a las generaciones jóvenes puede ser leído simplemente como un espacio amenazante que conduzca a petrificar ciertas formas tradicionales como una respuesta a los tiempos inestables y hostiles que corren. Detrás de una desconfianza de las generaciones mayores hacia los jóvenes y las acusaciones recíprocas de indiferencia de unos y de rigidez de otros, pueden esconderse respuestas paralizantes a un problema que ambos experimentan como real: ¿Cuál es el terreno propicio en que pueda acontecer la transmisión de la fe tradicional de una generación a otra? Pregunta que se hace más urgente por el desfase cada vez mayor, más heterogéneo y más rápido que se instala entre una generación y otra.

Para enfrentar este desafío se requiere discernir en el presente no solo amenazas sino también oportunidades. En el nuevo contexto en que se dan las experiencias religiosas en nuestro país marcado por un proceso por un lado de desinstitucionalización de las prácticas y desafiliación a las pertenencias colectivas y, por otro, de creciente individualización, ello no significa la desaparición de lo religioso sino una nueva configuración que estaría en curso. En efecto, lo religioso-católico -en el caso nuestropuede seguir siendo recibido por las nuevas generaciones, en la medida que sea presentado como un objeto no de selección aleatoria, motivada por las necesidades variables de los sujetos sino de elección, de algo fun-

31 Y.M. Congar, Je crois en l'Esprit Saint. III (Paris 1981), 11. 
damental para vivir y estructurar con sentido la propia vida, los proyectos biográficos y los sociales.

Esto representa una tarea tan vasta como la que señalábamos antes como una fundición de la Tradición. En clave de comunicación, implica que los mismos agentes de la transmisión hayan experimentado en carne propia que lo central de la fe es recibido como un acontecimiento transformador, que configure sus modos de ver, de sentir, de pensar, de actuar y de situarse en el mundo. Es lo que probablemente constituye uno de los aportes mayores de la V Conferencia del Episcopado Latinoamericano y del Caribe, reunida en Aparecida, al poner el acento en que solo puede ser misionero - comunicador de la vida en abundancia que ofrece Jesúsquien es primero discípulo, que él mismo se ha dejado encontrar por Jesús que es la Vida y ha transformado su existencia en una proexistencia como la suya.

Supone también un esfuerzo decidido tanto de la acción pastoral como de la reflexión teológica que la acompaña por situarse en la perspectiva de su interlocutor de la comunicación. Ello no solo para conocer sus códigos de comunicación y adaptar pragmáticamente el mensaje sino para abrirse comunicador y receptor a un mensaje nuevo que surge precisamente del encuentro, del reconocimiento de una acción del Espíritu que precede a la comunicación de la fe. Ocurre, por tanto, algo inédito e imprevisible relacionado con Dios, también para el que lo presenta explícitamente cuando se dispone a buscar las formas que sean más adecuadas y significativas para el interlocutor y cuando se abre a lo que ya el Espíritu está operando en este último.

Esto implica además que la relación entre Iglesia y mundo, en lo que a la fe y a la Tradición se refiere, ya no se estructura sobre la lógica de preguntas que el mundo presuntamente se plantearía o que la Iglesia ayudaría a formular y las respuestas que esta, desde la fe, le presentaría como su servicio. Se trata más bien de estructurar estas relaciones sobre la base una lógica de preguntas-preguntas: ya sea porque reconocemos como nuestras las preguntas de los hombres, ya sea porque nos permitimos poner en estado de pregunta a los hombres, desde nuestra fe. Evidentemente no se trata de renunciar a la posibilidad de la respuesta, pero esta la buscamos juntos con los hombres y mujeres de nuestro tiempo, ofreciendo el Evangelio del que somos portadores como un camino de sentido -de salvación-que invitamos a recorrer por las sendas de los hombres, que 
son también las nuestras. De ello depende una de las formas que tenemos como Iglesia de asumir nuestra propia mundanidad constitutiva.

En lo que concierne a esta otra lógica de relación Iglesia-mundo, Congar, se reprochaba el no haber dado suficiente espacio a las preguntas que le venían de sus contemporáneos -reproche que pareciera provenir más bien de la sabiduría de los años que de un sentimiento inconfeso de culpa por una pusilanimidad intelectual para enfrentar las verdaderas preguntas-. Al mismo tiempo, valora como una oportunidad que le ofrece el tiempo presente el dar mayor espacio a las preguntas y a las búsquedas con los hombres y mujeres de hoy, en especial con los jóvenes:

«Me reprocho a veces no vivir suficientemente las preguntas, cortarlas demasiado rápido por las respuestas. En esas condiciones, ellas podrían ser solo respuestas a las cuestiones de anteayer o de ayer pero tal vez no las de hoy ni las de mañana. En la incertidumbre en la que parecen complacerse muchos jóvenes ¿No hay allí una riqueza de espíritu que me haría falta un poco?» ${ }^{32}$.

Ello no le hace de ningún modo renunciar a la Tradición, pues le da un lugar, un medio y hace de él un testigo, al mismo tiempo que le ofrece un impulso nuevo para situarse en el tiempo presente, por incierto que parezca. Lo que señala Congar estimo válido para todo testigo de la Tradición:

«Pero mi rol -si tengo alguno- sería ser sin duda un testigo de la tradición en medio del cambio: siendo la Tradición completamente otra cosa que una afirmación mecánica y repetitiva del pasado: es la presencia activa de un principio en toda su historia) ${ }^{33}$.

Se trata de pensar el conjunto de la Tradición de la fe en clave de proposición, de oferta significativa no solo para el que la comunica sino además deseable y razonable para el que la recibe. Este paso lo encontramos por ejemplo en el esfuerzo realizado por la Iglesia de Francia que duró más de cuatro años (1994-1997), en que se pensó el conjunto de la vida pastoral de la Iglesia ya no en clave de herencia que se transmite sino en clave de proposición que se ofrece. El camino emprendido fue acorde con este propósito: hubo encuentros de pastores con los fieles y de estos con recomenzantes y con personas alejadas o situadas fuera de la Iglesia. También la forma en que se expresó ese camino reflexivo hablaba por sí misma de lo que se quería comunicar: una carta dirigida en primer lugar a los

32 J. PuYo, Une vie pour la vérité. Jean Puyo interroge le Père Congar, 238.

33 J. PuYo, Une vie pour la vérité. Jean Puyo interroge le Père Congar, 239. 
católicos de Francia para proponer la fe en la sociedad actual. Esta carta iba dirigida también a los hermanos de las iglesias protestante y ortodoxa, a los hombres y mujeres de otras confesiones y tradiciones religiosas e incluso a los hombres y mujeres que se interesan en el lugar y futuro de la fe cristiana en la sociedad actual, aun cuando no compartan las mismas convicciones creyentes ${ }^{34}$. En esta misma perspectiva se sitúa el esfuerzo teológico de síntesis y de divulgación inteligente de la fe realizado por el teólogo Bernard Sesboüé, en donde propone un panorama del conjunto de la fe católica expresada en el Credo y tematizada a lo largo de la historia en la Tradición de la Iglesia. En coherencia con este propósito de fondo, el autor presenta su libro -jde más de 650 páginas!- como una invitación a creer. En cuanto invitación, sitúa esta obra «en un clima de libertad mutua y de gratuidad entre el autor y el lector. El primero no desea imponerle nada al segundo, ni exhortarlo a lo que quiera que sea. El segundo, por su parte, no está obligado a nada. Es invitado simplemente a entrar en un diálogo de hombre a hombre y a recorrer un camino en relación con cuestiones de hombre». Y en cuanto invitación a creer, apunta a entrar en el acto de creer que supone «un acto de libertad personal que ningún otro puede realizar en nuestro lugar» y, a la vez, «ciertas condiciones [...], superar numerosos obstáculo en nosotros y fuera de nosotros» $\rangle^{35}$.

El mismo espíritu de invitación es el que anima al documento de la Conferencia Episcopal de Chile, En camino al bicentenario, presentado en septiembre de 2004. El acontecimiento que lo motiva es el Bicentenario de la independencia de nuestro país que involucra a todos los chilenos y chilenas. Se trata de una proposición dirigida a los católicos, creyentes adultos, a quienes la Iglesia considera como instauradores del orden temporal, así como a los hermanos o hermanas cristianos y no cristianos, creyentes y no creyentes, «con el fin de escucharlos, enriquecer nuestras reflexiones y llegar, eventualmente, a un documento más maduro y representativo» ${ }^{36}$. Para lograr este propósito el documento fue presentado en la forma no de un texto magisterial -vinculante para el pueblo cristiano- sino de un documento de trabajo para «estimular la reflexión y

34 Les ÉvêQues De France, Proposer la foi dans la société actuelle III. Lettre aux catholiques de France (Paris, 1997).

35 B. SesBoüE, Creer. Invitación a la fe católica para las mujeres y los hombres del siglo XXI. Traducido por J. Padilla Moreno (Magister 7; Madrid 2000) 7.

36 Conferencia Episcopal de Chile, En camino al bicentenario. En el mes de la patria 2004, no $10,7$. 
ayudar $\rangle^{37}$ a los destinatarios invitándoles a sopesar sus responsabilidades en la construcción del país.

Si la perspectiva de la invitación y de la proposición fuera una perspectiva adecuada para situarnos en la coyuntura actual del país y de la Iglesia, podríamos imaginar lo que significaría repensar la liturgia, la moral, la iniciación sacramental y la teología misma desde esta óptica. Si nos situáramos más decididamente en esta perspectiva, probablemente no solo la transmisión de la Tradición de la fe podría ser un tesoro que una generación le ofrece a otra sino también ese tesoro mismo sería comprendido en su perenne novedad y ofrecimiento, bajo la forma presente y definitiva de la comensalidad: «Ten en cuenta que estoy a la puerta y voy a llamar: y, si alguno oye mi voz y me abre, entraré en su casa y cenaremos juntos los dos» (Ap 3, 20).

37 Conferencia Episcopal de Chile, En camino al bicentenario. En el mes de la patria 2004, no $10,7$. 
Resumen: En un contexto de crisis de transmisión de la cultura y de la fe cristiana de una generación a otra se hace urgente preguntarse por la dinámica que define a la Tradición de la Iglesia y su articulación dialéctica con las tradiciones que la alimentan y expresan a los largo de la historia. Para ello, estudiamos dicha articulación en la obra del teólogo francés Yves-Marie Congar. Esta lectura la hacemos en diálogo con el presente de nuestra cultura e Iglesia para discernir allí las oportunidades, resistencias y desafíos que se ofrecen tanto para la comprensión como para la comunicación de la Tradición eclesial.

Palabras clave: Crisis de la transmisión de la fe, Tradición y tradiciones, Yves-Marie Congar, proposición de la fe.

Abstract: In a context of a crisis of transmission of culture and the Christian faith from one generation to the next, it becomes urgent to question the dynamic that defines the Church Tradition and its dialectic articulation with the traditions that nourish and express it throughout history. To do this, we studied this articulation in the work of the French theologian Yves-Marie Congar. We did this reading in relation to the present state of our culture and Church to discern there the opportunities, strengths and challenges that are offered both for the understanding of and communication of the Ecclesiastical Tradition.

Keywords: faith transmission crisis, Tradition and traditions, Yves-Marie Congar, Proposition of faith. 